\title{
Aberrant pattern of regional cerebral blood flow in Alzheimer's disease: a voxel-wise meta-analysis of arterial spin labeling MR imaging studies
}

\author{
Hai Rong Ma1, Ping Lei Pan², Li Qin Sheng ${ }^{1}$, Zhen Yu Dai ${ }^{3}$, Gen Di Wang², Rong \\ $\mathrm{LuO}^{2}$, Jia Hui Chen ${ }^{2}$, Pei Rong Xiao' ${ }^{2}$, Jian Guo Zhong ${ }^{2}$ and Hai Cun Shi ${ }^{2}$ \\ ${ }^{1}$ Department of Neurology, Traditional Chinese Medicine Hospital of Kunshan, Kunshan, PR China \\ ${ }^{2}$ Department of Neurology, Affiliated Yancheng Hospital, School of Medicine, Southeast University, Yancheng, PR China \\ ${ }^{3}$ Department of Radiology, Affiliated Yancheng Hospital, School of Medicine, Southeast University, Yancheng, PR China \\ Correspondence to: Jian Guo Zhong, email: yc3yjgzhong@163.com \\ Hai Cun Shi, email: yc3yhcshi@gmail.com
}

Keywords: Alzheimer's disease, arterial spin labeling, default mode network, meta-analysis, seed-based d mapping

Received: May 18, 2017

Accepted: September 20, 2017

Published: October 04, 2017

Copyright: Ma et al. This is an open-access article distributed under the terms of the Creative Commons Attribution License 3.0 (CC BY 3.0), which permits unrestricted use, distribution, and reproduction in any medium, provided the original author and source are credited.

\section{ABSTRACT}

Many studies have applied arterial spin labeling (ASL) to characterize cerebral perfusion patterns of Alzheimer's disease (AD). However, findings across studies are not conclusive. A quantitatively voxel-wise meta-analysis to pool the resting-state ASL studies that measure regional cerebral blood flow (rCBF) alterations in AD was conducted to identify the most consistent and replicable perfusion pattern using seedbased d mapping. The meta-analysis, including 17 ASL studies encompassing 327 AD patients and 357 healthy controls, demonstrated that decreased rCBF in AD patients relative to healthy controls were consistently identified in the bilateral posterior cingulate cortices (PCC)/precuneus, bilateral inferior parietal lobules (IPLs), and left dorsolateral prefrontal cortex. The meta-regression analysis showed that more severe cognitive impairment in the AD samples correlated with greater decreases of rCBF in the bilateral PCC and left IPL. This study characterizes an aberrant ASL-rCBF perfusion pattern of $A D$ involving the posterior default mode network and executive network, which are implicated in its pathophysiology and hold promise for developing imaging biomarkers.

\section{INTRODUCTION}

Alzheimer's disease (AD), the most prevalent type of dementia in the aging population [1-3], is featured by memory disturbance, attentional and executive deficits, and visuospatial and perceptual impairments [4]. The neuropathological hallmark of $\mathrm{AD}$ is the progressive accumulation of amyloid beta $(A \beta)$ plaques and tau-related neurofibrillary tangles, and eventually accompanied by the damage and death of neurons in the brain [5]. The underlying neurobiology is far from being complete and no effective medications are available today for $\mathrm{AD}$ to slow or halt the damage and destruction of neurons [2]. This disorder has caused a substantial burden not only on the patients and their caregivers but also on the socioeconomic system [6]. Understanding the neural basis and early detection of AD are therefore very important.

Arterial spin labeling (ASL) MR imaging is a noninvasive technique that can quantitatively measure cerebral blood flow (CBF) by magnetically labelling the inflowing arterial blood water in vivo as an endogenous tracer [7-9]. ASL allows an automated voxel-by-voxel statistical analysis for regional $\mathrm{CBF}$ (rCBF) differences without any priori hypothesis [10-12]. Regional CBF is recognized as a reflection of intrinsic neural activity and brain physiology, which has been validated in normal aging and neuropsychiatric disorders [13-15]. ${ }^{18}$ Fluorodeoxyglucose positron emission tomography (FDG-PET) imaging biomarkers have been proposed by the National Institute on Aging and the Alzheimer's Association for detecting AD [16]. Perfusion pattern measured by ASL 
in the AD brain is closely matched with the metabolism pattern measured using PET [10, 17-20]. In addition, ASL offers a similar diagnostic ability as PET in the detection of AD [18-21]. Owing to its ease of acquisition, non-invasiveness, non-radiation, and reliability, ASL is increasingly proposed as an alternative to PET and holds promise for developing imaging biomarkers [13, 15, 22].

In the last decade, a growing body of research has applied ASL to characterize cerebral perfusion patterns of $\mathrm{AD}$ [22]. Abnormalities of rCBF measured by restingstate ASL in patients with $\mathrm{AD}$ in comparison with healthy controls have been frequently reported in the temporoparietal and posterior cingulate regions $[10,17,19,23-36]$. However, the detailed findings typically varied across studies. Abnormalities of rCBF in the frontal $[10,12,17-19,23,29-31,35,37-40]$ and occipital regions $[11,27,36,41]$, basal ganglia [39, 42], thalamus [24, 41], and insula [24, 39, 42] have also been reported. Although majority of ASL studies in $\mathrm{AD}$ demonstrated hypoperfusion in the brain regions, some studies also showed hyperperfusion in several cerebral areas $[11,25,39]$. These inconsistences may be presumably attributed to the differences in sample sizes, heterogeneity in the demographic and clinical variables of the samples as well as the variations in the technical characteristics of image acquisition and analytical methodology.

Consequently, it would be of great interest for this study to conduct a timely meta-analysis of ASL studies to identify the most consistent and replicable perfusion pattern of $\mathrm{AD}$. This voxel-wise meta-analysis utilized the anisotropic effect-size version of seed-based $d$ mapping
(SDM) software [43, 44], which has been extensively applied in previous meta-analyses of neuroimaging studies for neuropsychiatric disorders [44-49].

\section{RESULTS}

\section{Included studies}

According to the strategy of literature search and study selection, a total of 17 ASL studies that investigated rCBF differences between 327 AD patients and 357 healthy controls were finally eligible for the meta-analysis $[10,11,23-30,37-42,50]$. Figure 1 presents a flow diagram of the studies that met the criteria for this metaanalysis. Of these included studies, thirteen were published in English and the other four were in Chinese [30, 37, 40, 41]. Fourteen out of the 17 studies were performed on the 3.0T MRI scanning systems and the other three were on the 1.5T MRI systems. Regarding the techniques applied to measure resting-state $\mathrm{CBF}$ in these studies, ten studies used pulsed ASL (PASL); five used pseudocontinuous ASL (pCASL); and the remaining two used continuous ASL (CASL). The quality score of each included study was no less than 8.5 (total score $=10)$, which indicates that the quality is acceptable. Table 1 summarizes the demographic, clinical, and technical characteristics as well as the quality scores of the ASL studies included in the meta-analysis. Supplementary Table 1 presents the diagnostic criteria, disease stage, cognitive test, and vascular burden assessment for $\mathrm{AD}$ of the included studies in the meta-analysis.

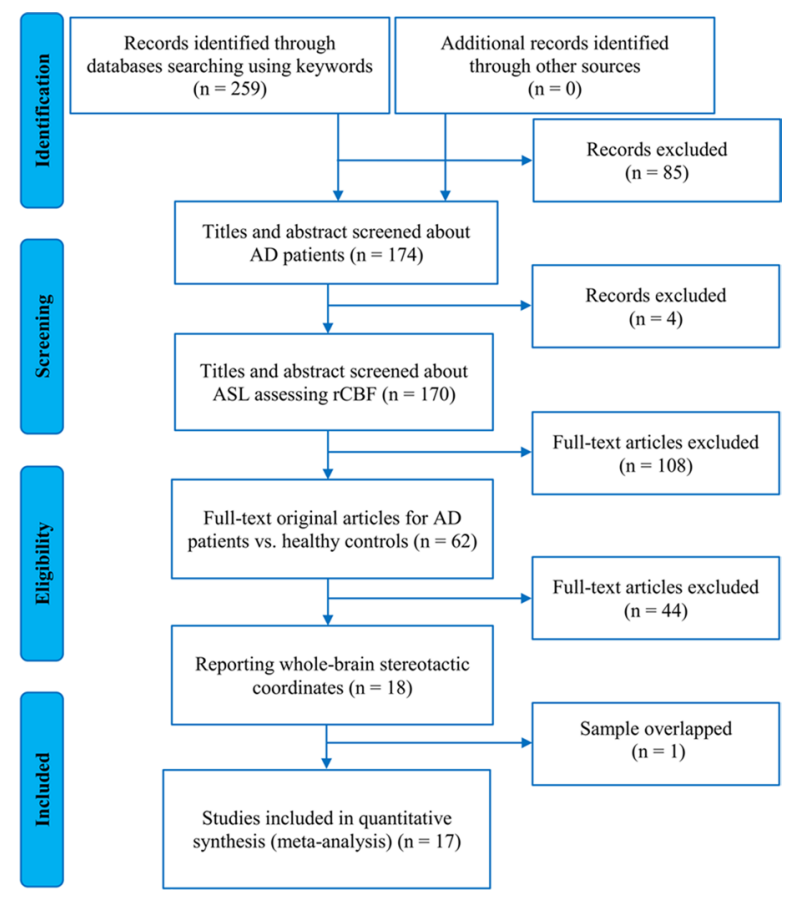

Figure 1: Flow diagram of the study selection procedure for the meta-analysis. Abbreviations: AD, Alzheimer's disease; ASL, arterial spin labeling, rCBF, regional cerebral blood flow. 
Table 1: Characteristics of ASL studies included in the meta-analysis

\begin{tabular}{|c|c|c|c|c|c|c|c|c|c|c|}
\hline \multirow{3}{*}{$\begin{array}{l}\text { Study } \\
\text { Johnson et al., } \\
2005\end{array}$} & \multicolumn{2}{|c|}{ Sample (female) } & \multirow{2}{*}{$\begin{array}{c}\text { Mean Age (SD) } \\
72.9(10.8)\end{array}$} & \multirow{2}{*}{$\begin{array}{c}\text { MMSE (SD) } \\
21.0 \text { (NA) }\end{array}$} & \multirow{2}{*}{$\begin{array}{c}\begin{array}{c}\text { Scanner } \\
\text { Strength }\end{array} \\
1.5 \mathrm{~T}\end{array}$} & \multirow{2}{*}{$\begin{array}{c}\begin{array}{c}\text { Imaging } \\
\text { technique }\end{array} \\
\text { PASL }\end{array}$} & \multirow{2}{*}{$\begin{array}{c}\text { Software } \\
\text { SPM99 }\end{array}$} & \multirow{2}{*}{$\frac{\text { FWHM }}{12 \mathrm{~mm}}$} & \multirow{2}{*}{$\begin{array}{c}\text { Threshold } \\
0.05, \text { corrected }\end{array}$} & \multirow{2}{*}{$\frac{\begin{array}{c}\text { Quality } \\
\text { score }^{\#}\end{array}}{9.0}$} \\
\hline & $\mathrm{AD}$ & $20(7)$ & & & & & & & & \\
\hline & $\mathrm{HC}$ & $23(13)$ & $72.9(8.2)$ & 29.4 (NA) & & & & & & \\
\hline \multirow{2}{*}{$\begin{array}{l}\text { Alsop et al., } \\
2008\end{array}$} & $\mathrm{AD}$ & $22(12)$ & $75.6(9.2)$ & $22.2(5.9)$ & $3.0 \mathrm{~T}$ & CASL & SPM2 & $8 \mathrm{~mm}$ & 0.05, uncorrected & 9.5 \\
\hline & $\mathrm{HC}$ & $16(9)$ & $72.6(8.9)$ & $27.9(2.6)$ & & & & & & \\
\hline \multirow{2}{*}{$\begin{array}{l}\text { Asllani et al., } \\
2008\end{array}$} & $\mathrm{AD}$ & $12(5)$ & 70.7 (8.7) & $38.7(11.1)^{*}$ & $1.5 \mathrm{~T}$ & CASL & SPM99 & $6 \mathrm{~mm}$ & 0.05 , corrected & 9.5 \\
\hline & $\mathrm{HC}$ & $20(12)$ & $72.1(6.5)$ & $53.5(2.8)^{*}$ & & & & & & \\
\hline \multirow{2}{*}{$\begin{array}{l}\text { Yoshiura et al., } \\
2009\end{array}$} & $\mathrm{AD}$ & $20(10)$ & $73.5(9.6)$ & $20.4(4.3)$ & $3.0 \mathrm{~T}$ & PASL & SPM2 & $12 \mathrm{~mm}$ & 0.001 , uncorrected & 9.5 \\
\hline & $\mathrm{HC}$ & $23(12)$ & $72.9(6.7)$ & $29.3(0.9)$ & & & & & & \\
\hline \multirow{2}{*}{$\begin{array}{l}\text { Cantin et al., } \\
2011\end{array}$} & $\mathrm{AD}$ & $9(5)$ & $71.1(6.7)$ & $21.7(2.2)$ & $1.5 \mathrm{~T}$ & PASL & SPM5 & $12 \mathrm{~mm}$ & 0.05, corrected & 8.5 \\
\hline & $\mathrm{HC}$ & $11(6)$ & $65.4(9.3)$ & $29.5(0.5)$ & & & & & & \\
\hline \multirow{2}{*}{$\begin{array}{l}\text { Chen et al., } \\
2011\end{array}$} & $\mathrm{AD}$ & $15(9)$ & $72.0(6.3)$ & $19.9(5.9)$ & $3.0 \mathrm{~T}$ & pCASL & SPM5 & $12 \mathrm{~mm}$ & 0.005 , uncorrected & 9.5 \\
\hline & $\mathrm{HC}$ & $19(12)$ & $69.2(7.6)$ & $29.5(1.0)$ & & & & & & \\
\hline \multirow{2}{*}{$\begin{array}{l}\text { Dashjamts et al., } \\
2011\end{array}$} & $\mathrm{AD}$ & $23(14)$ & $74.6(8.9)$ & $21.1(4.4)$ & $3.0 \mathrm{~T}$ & PASL & SPM8 & $12 \mathrm{~mm}$ & 0.001 , uncorrected & 9.5 \\
\hline & $\mathrm{HC}$ & $23(12)$ & $73.2(6.9)$ & $29.4(0.9)$ & & & & & & \\
\hline \multirow{2}{*}{$\begin{array}{l}\text { Alexopoulos } \\
\text { et al., } \\
2012\end{array}$} & $\mathrm{AD}$ & $19(8)$ & $72.0(9.4)$ & NA & $3.0 \mathrm{~T}$ & PASL & SPM5 & $12 \mathrm{~mm}$ & 0.001 , uncorrected & 8.5 \\
\hline & $\mathrm{HC}$ & $24(16)$ & $67.1(6.1)$ & NA & & & & & & \\
\hline \multirow{2}{*}{$\begin{array}{l}\text { Mak et al., } \\
2012\end{array}$} & $\mathrm{AD}$ & $20(15)$ & $75.4(6.75)$ & $16.3(4.55)$ & $3.0 \mathrm{~T}$ & PASL & SPM5 & $8 \mathrm{~mm}$ & 0.001 , uncorrected & 9.0 \\
\hline & $\mathrm{HC}$ & $20(17)$ & 70.8 (5.99) & $28.5(2.00)$ & & & & & & \\
\hline \multirow{2}{*}{$\begin{array}{l}\text { Grieder et al., } \\
2013\end{array}$} & $\mathrm{AD}$ & 14 (NA) & $66.5(9.6)$ & $24.8(3.9)$ & $3.0 \mathrm{~T}$ & pCASL & SPM8 & $8 \mathrm{~mm}$ & 0.05, corrected & 9.0 \\
\hline & $\mathrm{HC}$ & 19 (NA) & $69.5(3.1)$ & $28.7(0.9)$ & & & & & & \\
\hline \multirow{2}{*}{$\begin{array}{l}\text { Kim et al., } \\
2013\end{array}$} & $\mathrm{AD}$ & $25(21)$ & $70.9(9.8)$ & 17.2 (NA) & $3.0 \mathrm{~T}$ & PASL & SPM5 & $12 \mathrm{~mm}$ & 0.005 , uncorrected & 9.0 \\
\hline & $\mathrm{HC}$ & $25(16)$ & $68.4(5.6)$ & 27.3(NA) & & & & & & \\
\hline \multirow{2}{*}{$\begin{array}{l}\text { Zhang and Fan, } \\
2013\end{array}$} & $\mathrm{AD}$ & $16(10)$ & $76.00(7.12)$ & $19.25(4.97)$ & $3.0 \mathrm{~T}$ & pCASL & SPM8 & NA & 0.001 , uncorrected & 9.0 \\
\hline & $\mathrm{HC}$ & $16(12)$ & 70.75 (7.95) & $28.75(0.93)$ & & & & & & \\
\hline \multirow{2}{*}{$\begin{array}{l}\text { Zhang et al., } \\
2013\end{array}$} & $\mathrm{AD}$ & $17(12)$ & $66.92(8.91)$ & $15.92(4.32)$ & $3.0 \mathrm{~T}$ & PASL & SPM8 & NA & 0.05, corrected & 9.0 \\
\hline & $\mathrm{HC}$ & $17(12)$ & 66.07 (5.78) & $28.00(1.41)$ & & & & & & \\
\hline \multirow{2}{*}{$\begin{array}{l}\text { Ding et al., } \\
2014\end{array}$} & $\mathrm{AD}$ & $24(19)$ & 74.58 (6.678) & $16.0(3.9)$ & $3.0 \mathrm{~T}$ & pCASL & SPM8 & $6 \mathrm{~mm}$ & 0.05, corrected & 9.5 \\
\hline & $\mathrm{HC}$ & $21(13)$ & $69.64(5.884)$ & $29.4(1.0)$ & & & & & & \\
\hline \multirow{2}{*}{$\begin{array}{l}\text { Liu et al., } \\
2014\end{array}$} & $\mathrm{AD}$ & $16(10)$ & $75.3(6.9)$ & $18.69(5.50)$ & $3.0 \mathrm{~T}$ & pCASL & SPM8 & $6 \mathrm{~mm}$ & 0.05 , corrected & 9.5 \\
\hline & $\mathrm{HC}$ & $19(14)$ & $69.7(8.1)$ & $28.84(0.90)$ & & & & & & \\
\hline \multirow{2}{*}{$\begin{array}{l}\text { Lyu et al., } \\
2015\end{array}$} & $\mathrm{AD}$ & $30(15)$ & $68(10)$ & $21.6(1.6)$ & $3.0 \mathrm{~T}$ & PASL & SPM8 & $8 \mathrm{~mm}$ & 0.05 , corrected & 9.5 \\
\hline & $\mathrm{HC}$ & $30(19)$ & $52(8)$ & $29.0(1.0)$ & & & & & & \\
\hline \multirow{2}{*}{$\begin{array}{l}\text { Roquet et al., } \\
2016\end{array}$} & $\mathrm{AD}$ & $25(17)$ & $73.6(9.1)$ & $19.5(3.4)$ & $3.0 \mathrm{~T}$ & PASL & SPM8 & $8 \mathrm{~mm}$ & 0.05, corrected & 9.5 \\
\hline & $\mathrm{HC}$ & $21(12)$ & $64.8(8.6)$ & $28.9(1.0)$ & & & & & & \\
\hline
\end{tabular}

Abbreviations: ASL, arterial spin labeling, AD, Alzheimer's disease; HC, healthy controls; SD, standard deviation; MMSE, Mini-Mental State Examination; FWHM, full width at half maximum; NA, not available; PASL, pulsed arterial spin labeling; CASL, continuous arterial spin labeling; pCASL, pseudocontinuous arterial spin labeling; SPM, statistical parametric mapping; ", modified MMSE; ", a maximum score of 10 for each study.

\section{Regional CBF differences by pooling all included studies}

The voxel-wise SDM analysis demonstrated that decreased $\mathrm{rCBF}$ in $\mathrm{AD}$ patients compared to healthy controls were mainly located in the bilateral posterior cingulate cortices (PCC)/precuneus, bilateral inferior parietal lobules (IPLs), and left dorsolateral prefrontal cortex (DLPFC). In contrast, no regions showed significant increases of $\mathrm{rCBF}$ in $\mathrm{AD}$ patients relative to healthy controls. The SDM results are described in Table 2 and illustrated in Figure 2. 


\section{Reliability analysis}

The whole-brain jackknife sensitivity analysis revealed that decreases of $\mathrm{rCBF}$ in the bilateral $\mathrm{PCC} /$ precuneus and bilateral IPLs were the most robust findings, replicable in all 17 combinations. Decreases of rCBF in the left DLPFC remained highly replicable, as it was preserved in all but four in combinations of studies (Table 3).

\section{Publication bias analysis}

No publication biases for the identified brain regions with $\mathrm{rCBF}$ differences between $\mathrm{AD}$ patients and healthy controls were observed, which was revealed by the approximately symmetric funnel plots (Supplementary Figure 1) and the non-significant Egger's tests (Table 2).

\section{Meta-regression analysis}

The meta-regression analysis showed that lower Mini-Mental State Examination (MMSE) scores in the $\mathrm{AD}$ samples were associated with greater decreases of rCBF in the bilateral PCC (Peak Montreal Neurological Institute (MNI) coordinate at $\mathrm{x}=-4, \mathrm{y}=-22, \mathrm{z}=28 ; \mathrm{p}$ $=0.0000036 ;$ SDM-Z $=-1.97 ; 1149$ voxels $)$ and left IPL (Peak MNI coordinate at $\mathrm{x}=-38, \mathrm{y}=-52, \mathrm{z}=50 ; \mathrm{p}=$ 0.0000052 ; SDM-Z $=-1.92 ; 761$ voxels) (Figure 3).

\section{DISCUSSION}

To the best of our knowledge, this is the first quantitative meta-analysis to pool the resting-state ASL studies to identify the most consistent pattern of $\mathrm{rCBF}$ and to explore its clinical correlation in $\mathrm{AD}$. A total of
17 studies as measured with ASL in $327 \mathrm{AD}$ patients and 357 healthy controls were included in this voxel-wise meta-analysis. Decreases of rCBF in AD patients relative to healthy controls are consistently identified in the bilateral PCC/precuneus, bilateral IPLs, and left DLPFC. Furthermore, the meta-regression analysis indicates that more severe cognitive impairment in the $\mathrm{AD}$ samples was associated with greater decreases of $\mathrm{rCBF}$ in the bilateral PCC and left IPL.

The bilateral PCC/precuneus and bilateral IPLs, where this study observed the most consistent brain regions of decreased $\mathrm{rCBF}$ in $\mathrm{AD}$, are key nodes of the posterior default mode network (DMN) [51, 52]. The DMN, which is comprised of highly interconnected brain areas involved in higher cognitive functions, is the most active brain system at rest in healthy subjects [51]. There is compelling evidence suggesting that the $\mathrm{DMN}$, especially the posterior part is functionally and structurally impaired in AD patients [53-59] and atrisk subjects [12, 59-61]. Dysfunction of the DMN, a hallmark of $\mathrm{AD}$, has been linked to core memory, attentional, and visuospatial deficits [62, 63]. The DMN nodes, such as the PCC/precuneus, parietal and temporal lobes were confirmed to be more vulnerable to early amyloid deposition [54, 55, 64]. High amyloidbeta deposition in the DMN was demonstrated in AD patients [54, 65-68]. In addition, some studies suggest that decreases of $\mathrm{rCBF}$ in these regions, especially in the $\mathrm{PCC} /$ precuneus, may reflect a remote functional deficits caused by the neuronal damage in the medial temporal structures [10, 28, 69-72]. As such, decreases of rCBF in the bilateral PCC/precuneus and bilateral IPLs observed in this study may be a reflection of pathophysiological process that involves vascular dysfunction and neuronal degeneration underlying $\mathrm{AD}$ [14].

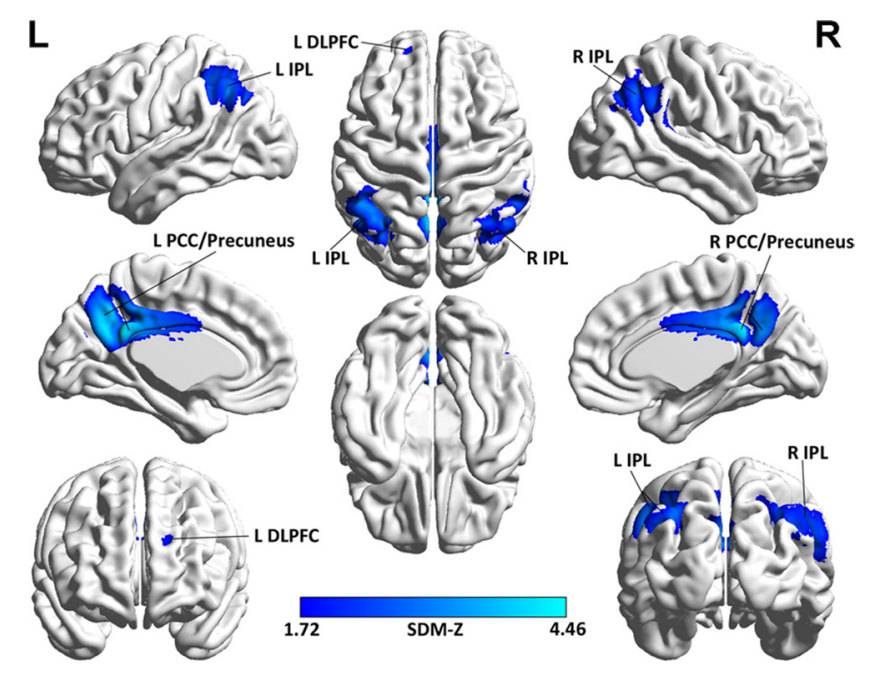

Figure 2: Brain map for the meta-analytic results of the 17 ASL studies comparing rCBF differences between AD patients and healthy controls. Abbreviations: ASL, arterial spin labeling, rCBF, regional cerebral blood flow; AD, Alzheimer's disease; L, left; R, right, IPL, inferior parietal lobule; DLPFC, dorsolateral prefrontal cortex; PCC, posterior cingulate cortex; SDM, Seedbased $d$ Mapping; The color bar indicates the maximum and the minimum absolute SDM-Z values. 
Table 2: Clusters of regional CBF differences in patients with AD relative to healthy controls

\begin{tabular}{lllllll}
\hline & Anatomical label & $\begin{array}{l}\text { Peak MNI coordinate } \\
(\mathbf{x}, \mathbf{y}, \mathbf{z})\end{array}$ & $\begin{array}{l}\text { Number } \\
\text { of voxels }\end{array}$ & $\begin{array}{l}\text { SDM-Z } \\
\text { value }\end{array}$ & $\begin{array}{l}\boldsymbol{p} \text { value } \\
\text { (SDM) }\end{array}$ & $\begin{array}{c}p \text { value } \\
\text { (Egger's test) }\end{array}$ \\
\hline Decreased regional CBF & Bilateral PCC/precuneus (BAs 23, 7, and 26) & $-2,-54,30$ & 4215 & -4.46 & $\sim 0$ & 0.051 \\
& Left IPL (BAs 40, 39, and 7) & $-50,-54,40$ & 2427 & -3.37 & $\sim 0$ & 0.15 \\
& Right IPL (BAs 40, 39, and 7) & $50,-60,38$ & 1161 & -2.89 & 0.0000041 & 0.29 \\
& Left DLPFC (BAs 9, 10, and 46) & $-18,52,30$ & 128 & -1.89 & 0.0021 & 0.070 \\
Increased regional CBF & None & & & & & \\
\hline
\end{tabular}

Abbreviations: CBF, cerebral blood flow; AD, Alzheimer's disease; MNI, Montreal Neurological Institute; SDM, Seed-based d Mapping; PCC, posterior cingulate cortex; IPL, inferior parietal lobule; DLPFC, dorsolateral prefrontal cortex; BA, Brodmann area.

The perfusion pattern identified in the current metaanalysis is largely in line with the metabolism pattern from the voxel-wise meta-analyses of FDG-PET studies in $\mathrm{AD}$ patients $[49,73]$. In addition, the perfusion pattern using ASL in AD are concordant with the perfusion pattern using other MRI modalities, such as $\mathrm{H}_{2}{ }^{15} \mathrm{O}-\mathrm{PET}$, ${ }^{99 \mathrm{~m}} \mathrm{Tc}$-hexamethylpropyleneamine oxime (HMPAO)-single photon emission computed tomography (SPECT), and ${ }^{99 \mathrm{~m}}$ Tc-ethyl cysteinate dimmer (ECD)-SPECT [73]. These data suggest that ASL provides information comparable to above invasive imaging techniques and shows potential as a reliable and safe alternative. The findings identified in the present voxel-wise meta-analysis are also consistent with the ASL studies using ROI analyses [10, 27, 34, 74, 75]. Decreases of $\mathrm{rCBF}$ in these areas could serve as specific regions of interest for a further diagnostic utility. Decreases of normalized $\mathrm{rCBF}$ in the bilateral PCC/ precuneus had an accuracy of $86.0 \%$ (91.3\% sensitivity and $80.0 \%$ specificity) in distinguishing $\mathrm{AD}$ patients from healthy controls [26]. Brain activity changes in the DMN may be an early marker for AD. Alexopoulos et al identified hypometabolism/hypoperfusion consistently in the DMN, especially the posterior part, such as the PCC/ precuneus and IPLs in amnestic mild cognitive impairment (aMCI) converters [73]. They further demonstrated that hypometabolism/hypoperfusion in the IPLs was the most reliable predictor of the progression from aMCI to $\mathrm{AD}$ [73]. A recent study observed a continuing decrease of $\mathrm{CBF}$ in the $\mathrm{PCC} /$ precuneus and other related regions in the continuum of $\mathrm{AD}$ [76]. Moreover, our meta-regression analysis shows that the severity of cognitive impairment in the $\mathrm{AD}$ samples was associated with the $\mathrm{rCBF}$ changes in the bilateral PCC and left IPL, which suggests that altered $\mathrm{rCBF}$ in these regions may act as an imaging marker for tracking disease progression.

Besides the areas of $\mathrm{rCBF}$ changes observed in the $\mathrm{DMN}$ in $\mathrm{AD}$ patients compared with healthy controls, we also identified the regions of decreased $\mathrm{rCBF}$ belonging to the central executive network (CEN), such as the DLPFC and posterior parietal areas $[77,78]$. The $\mathrm{CEN}$ is another intrinsic brain network that is known to be involved in executive functioning, particularly important for maintaining highlevel cognition $[78,79]$. Aberrant functional connectivity in the CEN was observed in AD [80-85]. Decreases of rCBF in the regions of the CEN probably account for the executive deficits in $\mathrm{AD}$ patients [79].

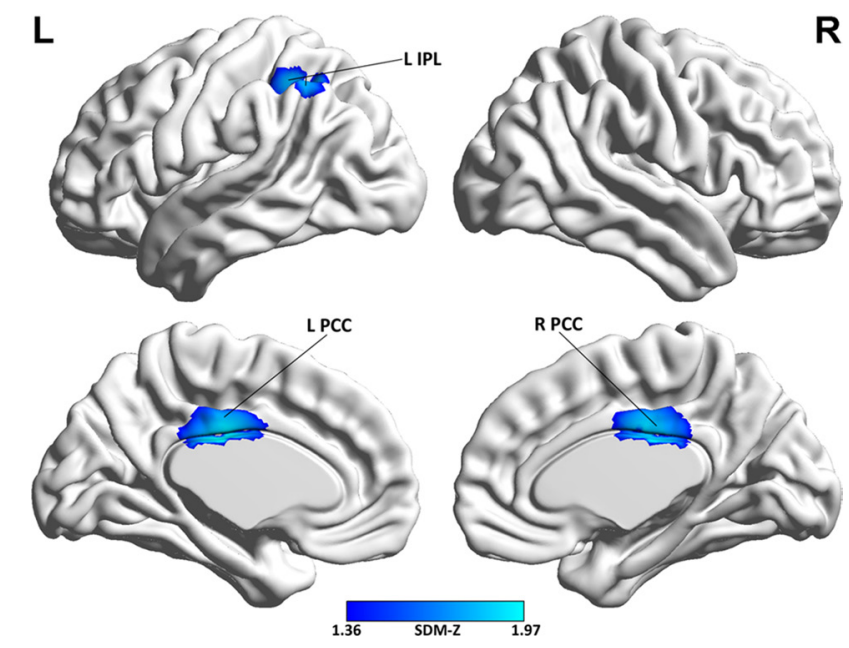

Figure 3: Brain map of the voxel-wise meta-regression analysis of MMSE scores in the AD samples. Abbreviations: MMSE, Mini-Mental State Examination; AD, Alzheimer's disease; L, left; R, right, IPL, inferior parietal lobule; PCC, posterior cingulate cortex; SDM, Seed-based $d$ Mapping; The color bar indicates the maximum and the minimum absolute SDM-Z values. 
Table 3: Jackknife sensitivity analysis

\begin{tabular}{|c|c|c|c|c|}
\hline All studies but ... & Bilateral PCC/precuneus & Left IPL & Right IPL & Left DLPFC \\
\hline Johnson et al., 2005 & yes & yes & yes & no \\
\hline Alsop et al., 2008 & yes & yes & yes & yes \\
\hline Asllani et al., 2008 & yes & yes & yes & yes \\
\hline Yoshiura et al., 2009 & yes & yes & yes & yes \\
\hline Cantin et al., 2011 & yes & yes & yes & yes \\
\hline Chen et al., 2011 & yes & yes & yes & yes \\
\hline Dashjamts et al., 2011 & yes & yes & yes & yes \\
\hline Alexopoulos et al., 2012 & yes & yes & yes & yes \\
\hline Mak et al., 2012 & yes & yes & yes & no \\
\hline Grieder et al., 2013 & yes & yes & yes & yes \\
\hline Kim et al., 2013 & yes & yes & yes & yes \\
\hline Zhang and Fan, 2013 & yes & yes & yes & yes \\
\hline Zhang et al., 2013 & yes & yes & yes & yes \\
\hline Ding et al., 2014 & yes & yes & yes & yes \\
\hline Liu et al., 2014 & yes & yes & yes & no \\
\hline Lyu et al., 2015 & yes & yes & yes & yes \\
\hline Roquet et al., 2016 & yes & yes & yes & yes \\
\hline Total & 17 out of 17 & 17 out of 17 & 17 out of 17 & 14 out of 17 \\
\hline
\end{tabular}

Abbreviations: PCC, posterior cingulate cortex; IPL, inferior parietal lobule; DLPFC, dorsolateral prefrontal cortex; yes, the region(s) reported; no, the region(s) not reported.

Atrophy of gray matter [86] and white matter [87] in the medial temporal lobe (MTL) is a characteristic and could serve as a neurostructural predictor of AD [88]. Interestingly, we did not observe consistent $\mathrm{rCBF}$ changes in MTL in AD patients relative to healthy controls in the present meta-analysis. This structural-functional discordance has been frequently detected in previous studies $[10,28,69-71,89]$, which is interpreted as a compensatory response to morphologic alterations [71]. Therefore, rCBF changes in the MTL may not be sensitive enough to distinguish healthy elders from $\mathrm{AD}$ patients, as aging-related tau pathology, hypometabolism, and hypoperfusion in the MTL were also observed in normalaged individuals [68, 90-92].

\section{Limitations and future perspectives}

Several limitations in this study should be acknowledged. First, a huge body of ASL studies in $\mathrm{AD}$ was excluded because of the chosen voxel-wise approach and this approach was based on summarized coordinates and their effect sizes rather than on raw imaging data or statistical brain maps, which might limit its accuracy [93]. In addition, the patients in the included studies were the clinical samples, who compared with community-based normal control volunteers. In this context, although they were matched or adjusted regarding age, sex ratio and education, some other critical factors, such as socioeconomic status, vascular risk burden, cognitive reserve, racial/ethnic make-up, and genetic vulnerability were not addressed in most of the original studies, which might lead to some heterogeneity in the conclusions and remains to be further addressed. Further analysis of multicenter raw imaging data in large homogeneous samples, like ASL-MRI scans from the Alzheimer's disease Neuroimaging Initiative (ADNI) subjects [94], would confirm the present findings. Second, our meta-analysis that synthesized the findings from the cross-sectional studies could not determine whether decreases of $\mathrm{rCBF}$ in the identified brain areas are the cause or consequence of AD [14]. Longitudinal studies could provide further insights. Third, ASL acquisition parameters, pre- and post-processing steps, such as scanner field-strength, inversion time, labeling duration, post label time delay, volume coverage, readout approaches, partial volume correction, and GM correction, may bias the results that warrant careful consideration by investigators. Further investigations in high field-strength MRI scanners with optimized and standardized imaging acquisition and analytical methodology are recommended [15]. 


\section{MATERIALS AND METHODS}

\section{Literature search and study selection}

A comprehensive literature search was performed in the PubMed, Web of Science, and Embase databases up until 16 December, 2016, using the keywords "Alzheimer's Disease" AND "arterial spin labeling". The China National Knowledge Infrastructure (CNKI) database was searched for additional studies published in Chinese. Reference lists from relevant studies were manually reviewed for further eligible studies. Studies were included in the meta-analysis if they met the following criteria: 1) the study used the standard diagnostic criteria for Alzheimer's Disease [9599]; 2) the study utilized resting-state ASL MR imaging to measure rCBF differences between Alzheimer's Disease and healthy controls; 3 ) the study applied a voxel-based statistical analysis; 4) the study reported three-dimensional coordinates in Talairach or MNI space; and 5) the study was published as an original article (not as a letter or a meeting abstract or a comment) in a peer-reviewed journal. Studies were excluded if they specifically used region of interest (ROI) approaches. Studies were also excluded if they did not report significant results with three-dimensional peak coordinates. To avoid duplication, only the study with a larger sample size was included in case that the patient populations overlapped. The quality of each eligible study was evaluated with a 10-point checklist (Supplementary Table 2) based on previous neuroimaging meta-analyses [100, 101]. This study followed the MOOSE guidelines for the meta-analyses of observational studies [102].

\section{Data analysis}

\section{Main voxel-wise meta-analysis}

A meta-analysis of $\mathrm{rCBF}$ differences between $\mathrm{AD}$ patients and healthy controls was performed using the SDM software package (www.sdmproject.com). The SDM approaches have been described in detail previously [44-47, 93, 103-105]. We briefly summarized here. Peak coordinates and effect sizes (e.g., $t$-values) of rCBF differences between $\mathrm{AD}$ patients and healthy controls were firstly extracted from each study $[103,105]$. The SDM software then separately recreated a standard MNI map of rCBF for each study applying an anisotropic Gaussian kernel (full width at half maximum $[\mathrm{FWHM}]=20 \mathrm{~mm}$ ) $[44,103,105]$. The mean map was generated by voxelwise calculation of the mean of the study maps with a standard random-effects model, taking into account the sample size, the intra-study variability, and the betweenstudy heterogeneity $[44,103,105]$. To generate significant results and the final map of rCBF, we applied the default SDM kernel size and threshold (uncorrected voxel $p$ $=0.005$, peak height $Z=1$, cluster extent $=10$ voxels), which is equivalent to a corrected $p$ value of 0.05 and is found to optimally balance false positives and negatives $[103,105]$. Results were visualized with the BrainNet Viewer [106].

\section{Reliability analysis}

To test the reliability of the findings identified in the main voxel-wise meta-analysis, a whole-brain voxel-based jackknife sensitivity analysis was performed by iteratively repeating the same analysis, excluding one study at a time $[44,46,93,103]$.

\section{Analysis of publication bias}

Possible publication bias was examined with a standard meta-analysis using the Stata 12.0 software (Stata Corp LP, College Station, TX, USA) by extracting the values from the relevant peaks from the main voxel-wise meta-analysis. An asymmetric funnel plot and a $p$-value less than 0.05 for Egger's test were considered significant.

\section{Meta-regression analysis}

A meta-regression analysis was conducted to assess the severity of cognitive impairment examined by MMSE scores that correlate with the ASL results. A stringent threshold of $p=0.0005$ and a cluster extent of 10 voxels were used for the meta-regression analysis [103, 104].

\section{CONCLUSIONS}

Our study shows the most consistent and replicable decreases of rCBF in the bilateral PCC/precuneus, bilateral IPLs, and left DLPFC in AD patients compared with healthy controls via the voxel-wise meta-analysis of ASL studies. These aberrant regions predominantly involve in the default mode and central executive networks that are implicated in the AD pathophysiology. This study further demonstrates that reduced $\mathrm{rCBF}$ in the bilateral $\mathrm{PCC} /$ precuneus and left IPL was related to the severity of cognitive impairment in $\mathrm{AD}$ patients, which suggests that altered $\mathrm{rCBF}$ in these regions may act as an objective imaging marker for tracking AD progression.

\section{Abbreviations}

$\mathrm{AD}$, Alzheimer's disease; ADNI, Alzheimer's disease Neuroimaging Initiative; aMCI, amnestic mild cognitive impairment; ASL, arterial spin labeling; BA, Brodmann area; CASL, continuous arterial spin labeling; CBF, cerebral blood flow; CEN, central executive network; ECD-SPECT, 99mTc-ethyl cysteinate dimmer-single photon emission computed tomography; DLPFC, dorsolateral prefrontal cortex; DMN, default mode network; FDG-PET, ${ }^{18}$ Fluorodeoxyglucose positron emission tomography; FWHM, full width at 
half maximum; HC, healthy controls; HMPAO-SPECT, 99mTc-hexamethylpropyleneamine oxime-single photon emission computed tomography; IPL, inferior parietal lobule; MMSE, Mini-Mental State Examination; MNI, Montreal Neurological Institute; PCC, posterior cingulate cortex; pCASL, pseudocontinuous arterial spin labeling; PASL, pulsed arterial spin labeling; NA, not available; rCBF, regional cerebral blood flow; ROI, region of interest; SDM, Seed-based $d$ Mapping; SD, standard deviation; SPM, statistical parametric mapping; CNKI, The China National Knowledge Infrastructure

\section{Author contributions}

HRM, PLP and SHC designed the protocol. HRM and HCS wrote the main manuscript. LQS, JHC and ZYD obtained the data. PLP, GDW and RL analyzed the results. PRX and JGZ revised the manuscript. All authors reviewed the manuscript.

\section{ACKNOWLEDGMENTS}

We are greatly indebted to the authors of the included studies.

\section{CONFLICTS OF INTEREST}

The authors declare no conflicts of interest.

\section{FUNDING}

This work was supported by the National Natural Science Foundation of China (Grant No. 81601161).

\section{REFERENCES}

1. Abrahamson EE, Foley LM, DeKosky ST, Hitchens TK, Ho C, Kochanek PM, Ikonomovic MD. Cerebral blood flow changes after brain injury in human amyloid-beta knockin mice. Journal of Cerebral Blood Flow and Metabolism. 2013; 33: 826-33. https://doi.org/10.1038/jcbfm.2013.24.

2. Scheltens P, Blennow K, Breteler MM, de Strooper B, Frisoni GB, Salloway S, Van der Flier WM. Alzheimer's disease. Lancet. 2016; 388:505-17. https://doi.org/10.1016/ S0140-6736(15)01124-1.

3. Goodman RA, Lochner KA, Thambisetty M, Wingo TS, Posner SF, Ling SM. Prevalence of dementia subtypes in United States Medicare fee-for-service beneficiaries, 2011-2013. Alzheimers Dement. 2017; 13:28-37. https:// doi.org/10.1016/j.jalz.2016.04.002.

4. Hodges JR. Alzheimer's centennial legacy: origins, landmarks and the current status of knowledge concerning cognitive aspects. Brain. 2006; 129:2811-22. https://doi. org/10.1093/brain/awl275.
5. Braak H, Braak E. Neuropathological stageing of Alzheimer-related changes. Acta Neuropathol. 1991; 82:239-59.

6. Alzheimer's Association. 2016 Alzheimer's disease facts and figures. Alzheimers Dement. 2016; 12:459-509.

7. Grade M, Hernandez Tamames JA, Pizzini FB, Achten E, Golay X, Smits M. A neuroradiologist's guide to arterial spin labeling MRI in clinical practice. Neuroradiology. 2015; 57:1181-202. https://doi.org/10.1007/s00234-0151571-z.

8. Williams DS, Detre JA, Leigh JS, Koretsky AP. Magnetic resonance imaging of perfusion using spin inversion of arterial water. Proc Natl Acad Sci U S A. 1992; 89:212-6.

9. Detre JA, Leigh JS, Williams DS, Koretsky AP. Perfusion imaging. Magn Reson Med. 1992; 23:37-45.

10. Chen Y, Wolk DA, Reddin JS, Korczykowski M, Martinez PM, Musiek ES, Newberg AB, Julin P, Arnold SE, Greenberg JH, Detre JA. Voxel-level comparison of arterial spin-labeled perfusion MRI and FDG-PET in Alzheimer disease. Neurology. 2011; 77:1977-85. https:// doi.org/10.1212/WNL.0b013e31823a0ef7.

11. Ding B, Ling HW, Zhang Y, Huang J, Zhang H, Wang T, Yan FH. Pattern of cerebral hyperperfusion in Alzheimer's disease and amnestic mild cognitive impairment using voxel-based analysis of 3D arterial spin-labeling imaging: initial experience. Clin Interv Aging. 2014; 9:493-500. https://doi.org/10.2147/cia.s58879.

12. Dai W, Lopez OL, Carmichael OT, Becker JT, Kuller LH, Gach HM. Mild cognitive impairment and alzheimer disease: patterns of altered cerebral blood flow at MR imaging. Radiology. 2009; 250:856-66. https://doi. org/10.1148/radiol.2503080751.

13. Haller S, Zaharchuk G, Thomas DL, Lovblad KO, Barkhof F, Golay X. Arterial spin labeling perfusion of the brain: Emerging clinical applications. Radiology. 2016; 281:337-56.

14. Zhang N, Gordon ML, Goldberg TE. Cerebral blood flow measured by arterial spin labeling MRI at resting state in normal aging and Alzheimer's disease. Neurosci Biobehav Rev. 2017; 72:168-75. https://doi.org/10.1016/j. neubiorev.2016.11.023.

15. Alsop DC, Detre JA, Golay X, Gunther M, Hendrikse J, Hernandez-Garcia L, Lu H, MacIntosh BJ, Parkes LM, Smits M, van Osch MJ, Wang DJ, Wong EC, et al. Recommended implementation of arterial spin-labeled perfusion MRI for clinical applications: A consensus of the ISMRM perfusion study group and the European consortium for ASL in dementia. Magn Reson Med. 2015; 73:102-16. https://doi.org/10.1002/mrm.25197.

16. McKhann GM, Knopman DS, Chertkow H, Hyman BT, Jack CR Jr, Kawas CH, Klunk WE, Koroshetz WJ, Manly JJ, Mayeux R, Mohs RC, Morris JC, Rossor MN, et al. The diagnosis of dementia due to Alzheimer's disease: recommendations from the National Institute on Aging- 
Alzheimer's Association workgroups on diagnostic guidelines for Alzheimer's disease. Alzheimers Dement. 2011; 7:263-9. https://doi.org/10.1016/j.jalz.2011.03.005.

17. Verclytte S, Lopes R, Lenfant P, Rollin A, Semah F, Leclerc $\mathrm{X}$, Pasquier F, Delmaire C. Cerebral Hypoperfusion and Hypometabolism Detected by Arterial Spin Labeling MRI and FDG-PET in Early-Onset Alzheimer's Disease. J Neuroimaging. 2016; 26:207-12. https://doi.org/10.1111/ jon.12264.

18. Tosun D, Schuff N, Rabinovici GD, Ayakta N, Miller BL, Jagust W, Kramer J, Weiner MM, Rosen HJ. Diagnostic utility of ASL-MRI and FDG-PET in the behavioral variant of FTD and AD. Ann Clin Transl Neurol. 2016; 3:740-51. https://doi.org/10.1002/acn3.330.

19. Verfaillie SC, Adriaanse SM, Binnewijzend MA, Benedictus MR, Ossenkoppele R, Wattjes MP, Pijnenburg YA, van der Flier WM, Lammertsma AA, Kuijer JP, Boellaard R, Scheltens P, van Berckel BN, et al. Cerebral perfusion and glucose metabolism in Alzheimer's disease and frontotemporal dementia: two sides of the same coin? Eur Radiol. 2015; 25:3050-9. https://doi.org/10.1007/s00330-015-3696-1.

20. Musiek ES, Chen Y, Korczykowski M, Saboury B, Martinez PM, Reddin JS, Alavi A, Kimberg DY, Wolk DA, Julin P, Newberg AB, Arnold SE, Detre JA. Direct comparison of fluorodeoxyglucose positron emission tomography and arterial spin labeling magnetic resonance imaging in Alzheimer's disease. Alzheimers Dement. 2012; 8:51-9. https://doi.org/10.1016/j.jalz.2011.06.003.

21. Tosun D, Schuff N, Jagust W, Weiner MW, Alzheimer"s Disease Neuroimaging Initiative. Discriminative Power of Arterial Spin Labeling Magnetic Resonance Imaging and 18F-Fluorodeoxyglucose Positron Emission Tomography Changes for Amyloid-beta-Positive Subjects in the Alzheimer's Disease Continuum. Neurodegener Dis. 2016; 16:87-94. https://doi.org/10.1159/000439257.

22. Zhang J. How far is arterial spin labeling MRI from a clinical reality? Insights from arterial spin labeling comparative studies in Alzheimer's disease and other neurological disorders. J Magn Reson Imaging. 2016; 43:1020-45. https://doi.org/10.1002/jmri.25022.

23. Johnson NA, Jahng GH, Weiner MW, Miller BL, Chui HC, Jagust WJ, Gorno-Tempini ML, Schuff N. Pattern of cerebral hypoperfusion in Alzheimer disease and mild cognitive impairment measured with arterial spin-labeling MR imaging: initial experience. Radiology. 2005; 234:8519. https://doi.org/10.1148/radiol.2343040197.

24. Asllani I, Habeck C, Scarmeas N, Borogovac A, Brown TR, Stern Y. Multivariate and univariate analysis of continuous arterial spin labeling perfusion MRI in Alzheimer's disease. Journal of Cerebral Blood Flow and Metabolism. 2008; 28:725-36. https://doi.org/10.1038/sj.jcbfm.9600570.

25. Alsop DC, Casement M, de Bazelaire C, Fong T, Press DZ. Hippocampal hyperperfusion in Alzheimer's disease. Neuroimage. 2008; 42:1267-74. https://doi.org/10.1016/j. neuroimage.2008.06.006.
26. Yoshiura T, Hiwatashi A, Noguchi T, Yamashita K, Ohyagi Y, Monji A, Nagao E, Kamano H, Togao O, Honda H. Arterial spin labelling at 3-T MR imaging for detection of individuals with Alzheimer's disease. Eur Radiol. 2009; 19:2819-25. https://doi.org/10.1007/s00330-009-1511-6.

27. Alexopoulos P, Sorg C, Forschler A, Grimmer T, Skokou M, Wohlschlager A, Perneczky R, Zimmer C, Kurz A, Preibisch C. Perfusion abnormalities in mild cognitive impairment and mild dementia in Alzheimer's disease measured by pulsed arterial spin labeling MRI. Eur Arch Psychiatry Clin Neurosci. 2012; 262:69-77. https://doi. org/10.1007/s00406-011-0226-2.

28. Dashjamts T, Yoshiura T, Hiwatashi A, Yamashita K, Monji A, Ohyagi Y, Kamano H, Kawashima T, Kira J, Honda H. Simultaneous arterial spin labeling cerebral blood flow and morphological assessments for detection of Alzheimer's disease. Acad Radiol. 2011; 18:1492-9. https://doi. org/10.1016/j.acra.2011.07.015.

29. Kim SM, Kim MJ, Rhee HY, Ryu CW, Kim EJ, Petersen ET, Jahng GH. Regional cerebral perfusion in patients with Alzheimer's disease and mild cognitive impairment: effect of APOE epsilon4 allele. Neuroradiology. 2013; 55:25-34. https://doi.org/10.1007/s00234-012-1077-X.

30. Liu Y, Yuan HS, Zeng XZ, Wang Z, Zhang N. Threedimensional arterial spin labeling in evaluation on cerebral blood flow in patients with Alzheimer disease. Chin J Med Imaging Technol. 2014; 30:693-7.

31. Alsop DC, Detre JA, Grossman M. Assessment of cerebral blood flow in Alzheimer's disease by spin-labeled magnetic resonance imaging. Ann Neurol. 2000; 47:93-100. https:// doi.org/10.1002/1531-8249(200001)47:1<93::aidana $15>3.0 . c 0 ; 2-8$.

32. Yoshiura T, Hiwatashi A, Yamashita K, Ohyagi Y, Monji A, Takayama Y, Nagao E, Kamano H, Noguchi T, Honda H. Simultaneous measurement of arterial transit time, arterial blood volume, and cerebral blood flow using arterial spinlabeling in patients with Alzheimer disease. AJNR Am J Neuroradiol. 2009; 30:1388-93. https://doi.org/10.3174/ ajnr.A1562.

33. Zhang Y, Schuff N, Ching C, Tosun D, Zhan W, Nezamzadeh M, Rosen HJ, Kramer JH, Gorno-Tempini ML, Miller BL, Weiner MW. Joint assessment of structural, perfusion, and diffusion MRI in Alzheimer's disease and frontotemporal dementia. Int J Alzheimers Dis. 2011; 2011:546871. https://doi.org/10.4061/2011/546871.

34. Binnewijzend MA, Kuijer JP, van der Flier WM, Benedictus MR, Moller CM, Pijnenburg YA, Lemstra AW, Prins ND, Wattjes MP, van Berckel BN, Scheltens P, Barkhof F. Distinct perfusion patterns in Alzheimer's disease, frontotemporal dementia and dementia with Lewy bodies. Eur Radiol. 2014; 24:2326-33. https://doi.org/10.1007/ s00330-014-3172-3.

35. Liu Y, Zeng X, Wang Z, Zhang N, Fan D, Yuan H. Different post label delay cerebral blood flow measurements in patients with Alzheimer's disease using 3D arterial spin 
labeling. Magn Reson Imaging. 2015; 33:1019-25. https:// doi.org/10.1016/j.mri.2015.05.001.

36. Le Heron CJ, Wright SL, Melzer TR, Myall DJ, MacAskill MR, Livingston L, Keenan RJ, Watts R, DalrympleAlford JC, Anderson TJ. Comparing cerebral perfusion in Alzheimer's disease and Parkinson's disease dementia: an ASL-MRI study. J Cereb Blood Flow Metab. 2014; 34:96470. https://doi.org/10.1038/jcbfm.2014.40.

37. Lyu YR, Li Q, Liu LW, Fan Y, Guo QH, He HJ, Feng XY. Application of cerebral MR perfusion imaging using pulsed arterial spin labeling technique in patients with amnestictype mild cognitive impairment and mild Alzheimer disease. Chin J Radiol. 2015; 49:900-6.

38. Mak HK, Chan Q, Zhang Z, Petersen ET, Qiu D, Zhang L, Yau KK, Chu LW, Golay X. Quantitative assessment of cerebral hemodynamic parameters by QUASAR arterial spin labeling in Alzheimer's disease and cognitively normal Elderly adults at 3-tesla. J Alzheimers Dis. 2012; 31:33-44. https://doi.org/10.3233/jad-2012-111877.

39. Roquet D, Sourty M, Botzung A, Armspach JP, Blanc F. Brain perfusion in dementia with Lewy bodies and Alzheimer's disease: an arterial spin labeling MRI study on prodromal and mild dementia stages. Alzheimers Res Ther. 2016; 8:29. https://doi.org/10.1186/s13195-016-0196-8.

40. Zhang N, Fan DS. Measurement of Cerebral Blood Flow Using Arterial Spin Labeling Magnetic Resonance Imaging in Patients with Alzheimer's Disease. Neural Injury And Functional Reconstruction. 2013; 8:109-13.

41. Zhang SJ, Wang ZQ, Liang PP, Zhao ZL, Lu J. Application of arterial spin labeling technique in cerebral perfusion imaging of patients with Alzheimer disease. Chin J Geriatr Heart Brain Vessel Dis. 2013; 15:35-8.

42. Grieder M, Crinelli RM, Jann K, Federspiel A, Wirth M, Koenig T, Stein M, Wahlund LO, Dierks T. Correlation between topographic $\mathrm{N} 400$ anomalies and reduced cerebral blood flow in the anterior temporal lobes of patients with dementia. J Alzheimers Dis. 2013; 36:711-31. https://doi. org/10.3233/jad-121690.

43. Radua J, Rubia K, Canales-Rodriguez EJ, Pomarol-Clotet E, Fusar-Poli P, Mataix-Cols D. Anisotropic kernels for coordinate-based meta-analyses of neuroimaging studies. Front Psychiatry. 2014; 5:13. https://doi.org/10.3389/ fpsyt.2014.00013.

44. Alegria AA, Radua J, Rubia K. Meta-Analysis of fMRI Studies of Disruptive Behavior Disorders. Am J Psychiatry. 2016; 173:1119-30. https://doi.org/10.1176/appi.ajp.2016.15081089.

45. Norman LJ, Carlisi C, Lukito S, Hart H, Mataix-Cols D, Radua J, Rubia K. Structural and Functional Brain Abnormalities in Attention-Deficit/Hyperactivity Disorder and Obsessive-Compulsive Disorder: A Comparative Metaanalysis. JAMA Psychiatry. 2016; 73:815-25. https://doi. org/10.1001/jamapsychiatry.2016.0700.

46. Pan P, Zhan H, Xia M, Zhang Y, Guan D, Xu Y. Aberrant regional homogeneity in Parkinson's disease: A voxel-wise meta-analysis of resting-state functional magnetic resonance imaging studies. Neurosci Biobehav Rev. 2017; 72:223-31. https://doi.org/10.1016/j.neubiorev.2016.11.018.

47. Wise T, Radua J, Nortje G, Cleare AJ, Young AH, Arnone D. Voxel-Based Meta-Analytical Evidence of Structural Disconnectivity in Major Depression and Bipolar Disorder. Biol Psychiatry. 2016; 79:293-302. https://doi. org/10.1016/j.biopsych.2015.03.004.

48. Iwabuchi SJ, Krishnadas R, Li C, Auer DP, Radua J, Palaniyappan L. Localized connectivity in depression: a meta-analysis of resting state functional imaging studies. Neurosci Biobehav Rev. 2015; 51:77-86. https://doi. org/10.1016/j.neubiorev.2015.01.006.

49. Goodkind M, Eickhoff SB, Oathes DJ, Jiang Y, Chang A, Jones-Hagata LB, Ortega BN, Zaiko YV, Roach EL, Korgaonkar MS, Grieve SM, Galatzer-Levy I, Fox PT, et al. Identification of a common neurobiological substrate for mental illness. JAMA Psychiatry. 2015; 72:305-15. https:// doi.org/10.1001/jamapsychiatry.2014.2206.

50. Cantin S, Villien M, Moreaud O, Tropres I, Keignart S, Chipon E, Le Bas JF, Warnking J, Krainik A. Impaired cerebral vasoreactivity to $\mathrm{CO} 2$ in Alzheimer's disease using BOLD fMRI. Neuroimage. 2011; 58:579-87. https://doi. org/10.1016/j.neuroimage.2011.06.070.

51. Buckner RL, Andrews-Hanna JR, Schacter DL. The brain's default network: anatomy, function, and relevance to disease. Ann N Y Acad Sci. 2008; 1124:1-38. https://doi. org/10.1196/annals.1440.011.

52. Krajcovicova L, Marecek R, Mikl M, Rektorova I. Disruption of resting functional connectivity in Alzheimer's patients and at-risk subjects. Curr Neurol Neurosci Rep. 2014; 14:491. https://doi.org/10.1007/ s11910-014-0491-3.

53. Celebi O, Uzdogan A, Oguz KK, Has AC, Dolgun A, Cakmakli GY, Akbiyik F, Elibol B, Saka E. Default mode network connectivity is linked to cognitive functioning and CSF Abeta1-42 levels in Alzheimer's disease. Arch Gerontol Geriatr. 2016; 62:125-32. https://doi. org/10.1016/j.archger.2015.09.010.

54. Buckner RL, Snyder AZ, Shannon BJ, LaRossa G, Sachs R, Fotenos AF, Sheline YI, Klunk WE, Mathis CA, Morris JC, Mintun MA. Molecular, structural, and functional characterization of Alzheimer's disease: evidence for a relationship between default activity, amyloid, and memory. J Neurosci. 2005; 25:7709-17. https://doi.org/10.1523/ jneurosci.2177-05.2005.

55. Grothe MJ, Teipel SJ, Alzheimer's Disease Neuroimaging Initiative. Spatial patterns of atrophy, hypometabolism, and amyloid deposition in Alzheimer's disease correspond to dissociable functional brain networks. Hum Brain Mapp. 2016; 37:35-53. https://doi.org/10.1002/hbm.23018.

56. Weiler M, de Campos BM, Nogueira MH, Pereira Damasceno B, Cendes F, Balthazar ML. Structural connectivity of the default mode network and cognition in Alzheimers disease. Psychiatry Res. 2014; 223:15-22. https://doi.org/10.1016/j.pscychresns.2014.04.008. 
57. Agosta F, Pievani M, Geroldi C, Copetti M, Frisoni GB, Filippi M. Resting state fMRI in Alzheimer's disease: beyond the default mode network. Neurobiol Aging. 2012; 33:1564-78. https://doi.org/10.1016/j. neurobiolaging.2011.06.007.

58. Damoiseaux JS, Prater KE, Miller BL, Greicius MD. Functional connectivity tracks clinical deterioration in Alzheimer's disease. Neurobiol Aging. 2012; 33:828.e1930. https://doi.org/10.1016/j.neurobiolaging.2011.06.024.

59. Li HJ, Hou XH, Liu HH, Yue CL, He Y, Zuo XN. Toward systems neuroscience in mild cognitive impairment and Alzheimer's disease: a meta-analysis of 75 fMRI studies. Hum Brain Mapp. 2015; 36:1217-32. https://doi. org/10.1002/hbm.22689.

60. Bai F, Zhang Z, Yu H, Shi Y, Yuan Y, Zhu W, Zhang X, Qian Y. Default-mode network activity distinguishes amnestic type mild cognitive impairment from healthy aging: a combined structural and resting-state functional MRI study. Neurosci Lett. 2008; 438:111-5. https://doi.org/10.1016/j. neulet.2008.04.021.

61. Rombouts SA, Barkhof F, Goekoop R, Stam CJ, Scheltens P. Altered resting state networks in mild cognitive impairment and mild Alzheimer's disease: an fMRI study. Hum Brain Mapp. 2005; 26:231-9. https://doi.org/10.1002/hbm.20160.

62. Teipel S, Grothe MJ, Zhou J, Sepulcre J, Dyrba M, Sorg C, Babiloni C. Measuring Cortical Connectivity in Alzheimer's Disease as a Brain Neural Network Pathology: Toward Clinical Applications. J Int Neuropsychol Soc. 2016; 22:138-63. https://doi.org/10.1017/S1355617715000995.

63. Jacobs HI, Radua J, Luckmann HC, Sack AT. Metaanalysis of functional network alterations in Alzheimer's disease: toward a network biomarker. Neurosci Biobehav Rev. 2013; 37:753-65. https://doi.org/10.1016/j. neubiorev.2013.03.009.

64. Buckner RL, Sepulcre J, Talukdar T, Krienen FM, Liu H, Hedden T, Andrews-Hanna JR, Sperling RA, Johnson KA. Cortical hubs revealed by intrinsic functional connectivity: mapping, assessment of stability, and relation to Alzheimer's disease. J Neurosci. 2009; 29:1860-73. https://doi.org/10.1523/JNEUROSCI.5062-08.2009.

65. Drzezga A, Grimmer T, Henriksen G, Stangier I, Perneczky R, Diehl-Schmid J, Mathis CA, Klunk WE, Price J, DeKosky S, Wester HJ, Schwaiger M, Kurz A. Imaging of amyloid plaques and cerebral glucose metabolism in semantic dementia and Alzheimer's disease. Neuroimage. 2008; 39:619-33. https://doi.org/10.1016/j. neuroimage.2007.09.020.

66. Frisoni GB, Lorenzi M, Caroli A, Kemppainen N, Nagren $\mathrm{K}$, Rinne JO. In vivo mapping of amyloid toxicity in Alzheimer disease. Neurology. 2009; 72:1504-11. https:// doi.org/10.1212/WNL.0b013e3181a2e896.

67. Hampel H. Amyloid-beta and cognition in aging and Alzheimer's disease: molecular and neurophysiological mechanisms. J Alzheimers Dis. 2013; 33:S79-86. https:// doi.org/10.3233/JAD-2012-129003.
68. Bischof GN, Jessen F, Fliessbach K, Dronse J, Hammes J, Neumaier B, Onur O, Fink GR, Kukolja J, Drzezga A, van Eimeren T, Alzheimer's Disease Neuroimaging Initiative. Impact of tau and amyloid burden on glucose metabolism in Alzheimer's disease. Ann Clin Transl Neurol. 2016; 3:9349. https://doi.org/10.1002/acn3.339.

69. Kawachi T, Ishii K, Sakamoto S, Sasaki M, Mori T, Yamashita F, Matsuda H, Mori E. Comparison of the diagnostic performance of FDG-PET and VBM-MRI in very mild Alzheimer's disease. Eur J Nucl Med Mol Imaging. 2006; 33:801-9. https://doi.org/10.1007/s00259005-0050-x.

70. Matsunari I, Samuraki M, Chen WP, Yanase D, Takeda N, Ono K, Yoshita M, Matsuda H, Yamada M, Kinuya S. Comparison of 18F-FDG PET and optimized voxel-based morphometry for detection of Alzheimer's disease: aging effect on diagnostic performance. J Nucl Med. 2007; 48:1961-70. https://doi.org/10.2967/jnumed.107.042820.

71. Matsuda H, Kitayama N, Ohnishi T, Asada T, Nakano $\mathrm{S}$, Sakamoto S, Imabayashi E, Katoh A. Longitudinal evaluation of both morphologic and functional changes in the same individuals with Alzheimer's disease. J Nucl Med. 2002; 43:304-11.

72. Teipel S, Grothe MJ, Alzheimer s Disease Neuroimaging Initiative. Does posterior cingulate hypometabolism result from disconnection or local pathology across preclinical and clinical stages of Alzheimer's disease? Eur J Nucl Med Mol Imaging. 2016; 43:526-36. https://doi.org/10.1007/ s00259-015-3222-3.

73. Schroeter ML, Stein T, Maslowski N, Neumann J. Neural correlates of Alzheimer's disease and mild cognitive impairment: a systematic and quantitative meta-analysis involving 1351 patients. Neuroimage. 2009; 47:1196-206. https://doi.org/10.1016/j.neuroimage.2009.05.037.

74. Steketee RM, Bron EE, Meijboom R, Houston GC, Klein S, Mutsaerts HJ, Mendez Orellana CP, de Jong FJ, van Swieten JC, van der Lugt A, Smits M. Early-stage differentiation between presenile Alzheimer's disease and frontotemporal dementia using arterial spin labeling MRI. Eur Radiol. 2016; 26:244-53. https://doi.org/10.1007/ s00330-015-3789-x.

75. Binnewijzend MA, Kuijer JP, Benedictus MR, van der Flier WM, Wink AM, Wattjes MP, van Berckel BN, Scheltens P, Barkhof F. Cerebral blood flow measured with 3D pseudocontinuous arterial spin-labeling MR imaging in Alzheimer disease and mild cognitive impairment: a marker for disease severity. Radiology. 2013; 267:221-30. https:// doi.org/10.1148/radiol.12120928.

76. Binnewijzend MA, Benedictus MR, Kuijer JP, van der Flier WM, Teunissen CE, Prins ND, Wattjes MP, van Berckel BN, Scheltens P, Barkhof F. Cerebral perfusion in the predementia stages of Alzheimer's disease. Eur Radiol. 2016; 26:506-14. https://doi.org/10.1007/s00330-015-3834-9.

77. Seeley WW, Menon V, Schatzberg AF, Keller J, Glover GH, Kenna H, Reiss AL, Greicius MD. Dissociable 
intrinsic connectivity networks for salience processing and executive control. J Neurosci. 2007; 27:2349-56. https:// doi.org/10.1523/JNEUROSCI.5587-06.2007.

78. Damoiseaux JS, Rombouts SA, Barkhof F, Scheltens P, Stam CJ, Smith SM, Beckmann CF. Consistent restingstate networks across healthy subjects. Proc Natl Acad Sci U S A. 2006; 103:13848-53. https://doi.org/10.1073/ pnas.0601417103.

79. Joo SH, Lim HK, Lee CU. Three Large-Scale Functional Brain Networks from Resting-State Functional MRI in Subjects with Different Levels of Cognitive Impairment. Psychiatry Investig. 2016; 13:1-7. https://doi.org/10.4306/ pi.2016.13.1.1.

80. Balachandar R, John JP, Saini J, Kumar KJ, Joshi H, Sadanand S, Aiyappan S, Sivakumar PT, Loganathan S, Varghese M, Bharath S. A study of structural and functional connectivity in early Alzheimer's disease using rest fMRI and diffusion tensor imaging. Int J Geriatr Psychiatry. 2015; 30:497-504. https://doi.org/10.1002/gps.4168.

81. Wang Z, Xia M, Dai Z, Liang X, Song H, He Y, Li K. Differentially disrupted functional connectivity of the subregions of the inferior parietal lobule in Alzheimer's disease. Brain Struct Funct. 2015; 220:745-62. https://doi. org/10.1007/s00429-013-0681-9.

82. Gour N, Felician O, Didic M, Koric L, Gueriot C, Chanoine V, Confort-Gouny S, Guye M, Ceccaldi M, Ranjeva JP. Functional connectivity changes differ in early and lateonset Alzheimer's disease. Hum Brain Mapp. 2014; 35:2978-94. https://doi.org/10.1002/hbm.22379.

83. Li L, Wu M, Liao Y, Ouyang L, Du M, Lei D, Chen L, Yao L, Huang X, Gong Q. Grey matter reduction associated with posttraumatic stress disorder and traumatic stress. Neurosci Biobehav Rev. 2014; 43:163-72. https://doi.org/10.1016/j. neubiorev.2014.04.003.

84. Dai Z, Yan C, Li K, Wang Z, Wang J, Cao M, Lin Q, Shu N, Xia M, Bi Y, He Y. Identifying and Mapping Connectivity Patterns of Brain Network Hubs in Alzheimer's Disease. Cereb Cortex. 2015; 25:3723-42. https://doi.org/10.1093/ cercor/bhu246.

85. Weiler M, Fukuda A, Massabki LH, Lopes TM, Franco AR, Damasceno BP, Cendes F, Balthazar ML. Default mode, executive function, and language functional connectivity networks are compromised in mild Alzheimer's disease. Curr Alzheimer Res. 2014; 11:274-82.

86. Yang J, Pan P, Song W, Huang R, Li J, Chen K, Gong Q, Zhong J, Shi H, Shang H. Voxelwise meta-analysis of gray matter anomalies in Alzheimer's disease and mild cognitive impairment using anatomic likelihood estimation. J Neurol Sci. 2012; 316:21-9. https://doi.org/10.1016/j. jns.2012.02.010.

87. Li J, Pan P, Huang R, Shang H. A meta-analysis of voxelbased morphometry studies of white matter volume alterations in Alzheimer's disease. Neurosci Biobehav Rev. 2012; 36:757-63. https://doi.org/10.1016/j. neubiorev.2011.12.001.
88. Ferreira LK, Diniz BS, Forlenza OV, Busatto GF, Zanetti MV. Neurostructural predictors of Alzheimer's disease: a meta-analysis of VBM studies. Neurobiol Aging. 2011; 32:1733-41. https://doi.org/10.1016/j. neurobiolaging.2009.11.008.

89. Ishii K, Sasaki H, Kono AK, Miyamoto N, Fukuda T, Mori E. Comparison of gray matter and metabolic reduction in mild Alzheimer's disease using FDG-PET and voxel-based morphometric MR studies. Eur J Nucl Med Mol Imaging. 2005; 32:959-63. https://doi.org/10.1007/s00259-004-1740-5.

90. Braak H, Thal DR, Ghebremedhin E, Del Tredici K. Stages of the pathologic process in Alzheimer disease: age categories from 1 to 100 years. J Neuropathol Exp Neurol. 2011; 70:960-9. https://doi.org/10.1097/ NEN.0b013e318232a379.

91. Asllani I, Habeck C, Borogovac A, Brown TR, Brickman AM, Stern Y. Separating function from structure in perfusion imaging of the aging brain. Hum Brain Mapp. 2009; 30:2927-35. https://doi.org/10.1002/hbm.20719.

92. Bangen KJ, Restom K, Liu TT, Jak AJ, Wierenga CE, Salmon DP, Bondi MW. Differential age effects on cerebral blood flow and BOLD response to encoding: associations with cognition and stroke risk. Neurobiol Aging. 2009; 30:1276-87. https://doi.org/10.1016/j. neurobiolaging.2007.11.012.

93. Radua J, Mataix-Cols D. Voxel-wise meta-analysis of grey matter changes in obsessive-compulsive disorder. $\mathrm{Br}$ J Psychiatry. 2009; 195:393-402. https://doi.org/10.1192/ bjp.bp.108.055046.

94. Yew B, Nation DA, Alzheimer's Disease Neuroimaging Initiative. Cerebrovascular resistance: effects on cognitive decline, cortical atrophy, and progression to dementia. Brain. 2017; 140:1987-2001. https://doi.org/10.1093/brain/awx112.

95. Criteria for the clinical diagnosis of Alzheimer's disease. Excerpts from the NINCDS-ADRDA Work Group report. J Am Geriatr Soc. 1985; 33:2-3.

96. McKhann G, Drachman D, Folstein M, Katzman R, Price D, Stadlan EM. Clinical diagnosis of Alzheimer's disease: report of the NINCDS-ADRDA Work Group under the auspices of Department of Health and Human Services Task Force on Alzheimer's Disease. Neurology. 1984; 34:939-44.

97. Frances A. (1994). Diagnostic and statistical manual of mental disorders: DSM-IV: American Psychiatric Association.

98. World Health Organization. (1992). The ICD-10 classification of mental and behavioural disorders: clinical descriptions and diagnostic guidelines: World Health Organization.

99. Dubois B, Feldman HH, Jacova C, Dekosky ST, BarbergerGateau P, Cummings J, Delacourte A, Galasko D, Gauthier S, Jicha G, Meguro K, O’Brien J, Pasquier F, et al. Research criteria for the diagnosis of Alzheimer's disease: revising the NINCDS-ADRDA criteria. Lancet Neurol. 2007; 6:73446. https://doi.org/10.1016/s1474-4422(07)70178-3. 
100. Li W, Chen Z, Wu M, Zhu H, Gu L, Zhao Y, Kuang W, Bi F, Kemp GJ, Gong Q. Characterization of brain blood flow and the amplitude of low-frequency fluctuations in major depressive disorder: A multimodal meta-analysis. J Affect Disord. 2017; 210:303-11. https://doi.org/10.1016/j. jad.2016.12.032.

101. Wang T, Liu J, Zhang J, Zhan W, Li L, Wu M, Huang H, Zhu H, Kemp GJ, Gong Q. Altered resting-state functional activity in posttraumatic stress disorder: A quantitative meta-analysis. Sci Rep. 2016; 6:27131. https://doi. org/10.1038/srep27131.

102. Stroup DF, Berlin JA, Morton SC, Olkin I, Williamson GD, Rennie D, Moher D, Becker BJ, Sipe TA, Thacker SB. Meta-analysis of observational studies in epidemiology: a proposal for reporting. Meta-analysis Of Observational Studies in Epidemiology (MOOSE) group. JAMA. 2000; 283:2008-12.

103. Radua J, Grau M, van den Heuvel OA, Thiebaut de Schotten M, Stein DJ, Canales-Rodriguez EJ, Catani M, Mataix-
Cols D. Multimodal voxel-based meta-analysis of white matter abnormalities in obsessive-compulsive disorder. Neuropsychopharmacology. 2014; 39:1547-57. https://doi. org/10.1038/npp.2014.5.

104. Radua J, Mataix-Cols D, Phillips ML, El-Hage W, Kronhaus DM, Cardoner N, Surguladze S. A new metaanalytic method for neuroimaging studies that combines reported peak coordinates and statistical parametric maps. Eur Psychiatry. 2012; 27:605-11. https://doi.org/10.1016/j. eurpsy.2011.04.001.

105. Lim L, Radua J, Rubia K. Gray matter abnormalities in childhood maltreatment: a voxel-wise meta-analysis. Am J Psychiatry. 2014; 171:854-63. https://doi.org/10.1176/appi. ajp.2014.13101427.

106. Xia M, Wang J, He Y. BrainNet Viewer: a network visualization tool for human brain connectomics. PLoS One. 2013; 8:e68910. https://doi.org/10.1371/journal. pone. 0068910 . 